University of Nebraska - Lincoln

DigitalCommons@University of Nebraska - Lincoln

Uniformed Services University of the Health

Sciences

U.S. Department of Defense

2008

Eye Malformations in Children with Heavy Alcohol Exposure in Utero

\author{
Elizabeth Y. Flanigan \\ National Institute of Child Health and Human Development \\ Sora Aros \\ University of Chile \\ Maria Ferraz Bueno \\ University of Chile \\ Mary Conley \\ National Institute of Child Health and Human Development \\ James F. Troendle \\ National Institute of Child Health and Human Development \\ See next page for additional authors
}

Follow this and additional works at: https://digitalcommons.unl.edu/usuhs

Part of the Medicine and Health Sciences Commons

Flanigan, Elizabeth Y.; Aros, Sora; Ferraz Bueno, Maria; Conley, Mary; Troendle, James F.; Cassorla, Fernando; and Mills, James L., "Eye Malformations in Children with Heavy Alcohol Exposure in Utero" (2008). Uniformed Services University of the Health Sciences. 6.

https://digitalcommons.unl.edu/usuhs/6

This Article is brought to you for free and open access by the U.S. Department of Defense at DigitalCommons@University of Nebraska - Lincoln. It has been accepted for inclusion in Uniformed Services University of the Health Sciences by an authorized administrator of DigitalCommons@University of Nebraska Lincoln. 


\section{Authors}

Elizabeth Y. Flanigan, Sora Aros, Maria Ferraz Bueno, Mary Conley, James F. Troendle, Fernando Cassorla, and James L. Mills 


\title{
Eye Malformations in Children with Heavy Alcohol Exposure in Utero
}

\author{
Elizabeth Y. Flanigan, MD, MPH, Sofia Aros, MD, Maria Ferraz Bueno, MD, Mary Conley, Ma, James F. Troendle, PhD, \\ Fernando Cassorla, MD, and James L. Mills, MD, MS
}

Objective To determine whether children who do not develop fetal alcohol syndrome (FAS) despite heavy alcohol exposure are at risk for eye abnormalities.

Study design We screened 9628 pregnant women and identified 101 women who were drinking $\geq 2$ oz of absolute alcohol per day and 101 nondrinking control women. We followed 43 exposed and 55 control offspring between age 4 and 9 years, performing masked standardized ophthalomologic examinations.

Results The groups did not differ in their rates of impaired visual acuity, refractory errors, ptosis, epicanthal folds, or short palpebral fissures. Biomicroscopy examination was normal in all exposed subjects; cataracts were detected in 2 control subjects (4\%) but in no exposed subjects. Arterial tortuosity was seen in 7 exposed subjects (16\%) and in 8 control subjects (15\%). Optic nerve hypoplasia was not detected in any subject.

Conclusions Previous research has found that children with FAS have a high incidence of serious ophthalmologic defects; our data indicate that the risk is limited to children with FAS and does not extend to children exposed to high levels of alcohol prenatally who do not develop FAS. Eye examinations are unlikely to clarify the diagnosis in children suspected of having alcohol-related damage. (J Pediatr 2008;153:391-5)

$\mathbf{P}$ renatal exposure to high levels of alcohol causes fetal alcohol spectrum disorders (FASD), a range of developmental abnormalities. Fetal alcohol syndrome (FAS), the most severe effect of prenatal alcohol exposure, is characterized by prenatal and postnatal growth restriction, developmental abnormalities, and malformations (most commonly craniofacial). ${ }^{1}$ Children who do not meet the criteria for FAS still may exhibit adverse effects of prenatal alcohol exposure, including physical anomalies, growth problems, developmental delays, and behavioral problems.

Numerous studies have reported that ophthalmologic abnormalities are an important finding in FASD. ${ }^{2-18}$ These disorders may include external eye malformations, intraocular abnormalities, and impaired visual acuity. ${ }^{3,4,19}$ Previous investigations had limitations, including studying only children with FAS who were referred for ophthalmologic evaluation because of known or suspected problems, providing little or no information on the extent of in utero alcohol exposure, performing limited evaluations of visual function, and examining only a small number of subjects. As a result, little is known regarding the risk of eye malformations in children who were exposed to high levels of alcohol in utero but did not develop FAS.

We conducted a prospective study of children born to women who consumed large amounts of alcohol (at least $2 \mathrm{oz}$ of absolute alcohol per day, or $\geq 48 \mathrm{~g} /$ day) during pregnancy and children of women who abstained from alcohol during pregnancy. The cohort was drawn from an unselected population of women attending a prenatal care facility in Santiago, Chile. Alcohol exposure was documented during the pregnancy. Each child underwent detailed ophthalmologic examinations, with the aim of identifying any association between heavy prenatal alcohol exposure and later ocular malformations and visual impairment.

\footnotetext{
From the Division of Epidemiology, Statistics, and Prevention Research, National Institute of Child Health and Human Development, National Institutes of Health, Department of Health and Human Services, Bethesda, MD (E.F., M.C., J.T., J.M.); Department of Pediatrics, School of Medicine, San Borja Arriaran Clinical Hospital, University of Chile, Santiago, Chile (S.A.); J.J. Aguirre Hospital, University of Chile, Santiago, Chile (M.B.); Department of Pediatrics, Uniformed Services University of the Health Sciences, Bethesda, MD (E.F.); Department of Pediatrics, Walter Reed Army Medical Center, Washington, DC (E.F.); and Institute of Maternal and Child Research, School of Medicine, University of Chile, Santiago, Chile (F.C.).

Supported by the National Institute of Child Health and Human Development's Intramural Research Program and protocol/ project OHSR-96-04

The views expressed are those of the authors and do not reflect the official policy of the Department of the Army, Department of Defense, or the United States Government. The authors declare no conflict of interest.

Submitted for publication Nov 9, 2007; last revision received Mar 19, 2008; accepted Apr 4, 2008

Reprint requests: Elizabeth Y. Flanigan, MD, $\mathrm{MPH}, 6100$ Executive Blvd, Room 7B03, $\mathrm{NICHD}, \mathrm{NIH}, \mathrm{DHHS}$, Bethesda, MD 20892. E-mail: eflanigan@usuhs.mil. 0022-3476/\$ - see front matter

Copyright (C) 2008 Mosby Inc. All rights reserved.

10.10 | 6/j.jpeds.2008.04.024
} 


\section{METHODS}

\section{Subjects}

The subjects were part of a prospective cohort study of the effects of prenatal exposure to alcohol on offspring of heavydrinking mothers in Chile, known as the National Institute of Child Health and Human Development (NICHD)-University of Chile Alcohol in Pregnancy Study. The study methods have been reported in detail previously. ${ }^{20}$ In brief, alcohol exposure was identified prenatally by interviewing 9628 (of 10 917) women who received prenatal care at a community health clinic serving approximately $60 \%$ of a lower-middle class population in Santiago, Chile, generally at their first prenatal visit, between August 1995 and July 2000. Those women suspected of heavy drinking $(n=887)$ had follow-up home visits to confirm their exposure status. These visits identified 101 women who were drinking at least $2 \mathrm{oz}$ ( $\geq 48 \mathrm{~g}$ ) of absolute alcohol per day on average. Unexposed subjects ( $n=101)$ were selected prenatally from the same cohort of women and were confirmed to be nondrinkers by home visits. The 2 groups were individually matched in terms of maternal age, parity, and gestational age at study entry. The study design was approved by the institutional review boards at the University of Chile and the NICHD. Each woman signed an informed consent form at the time of enrollment into the study.

The infants of these women were then followed prospectively for up to 11 years. Two children ( 1 in each group) were stillborn. The children $(n=200)$ were invited to undergo an ophthalmologic examination between December 2003 and January 2005.

\section{Ophthalmologic Examination}

All of the children were examined by a single ophthalmologist (M.B.), who was masked to the exposure group. The ophthalmologic examination included assessment of visual acuity (best-corrected visual acuity [BCVA]) and ocular motility, slit-lamp examination, fundus examination with both direct and indirect ophthalmoscopy, and refraction under cycloplegia. BCVA was tested with methods deemed suitable by the examiner for the child's age and developmental level (most commonly, the Snellen chart) and was recorded on the logMAR (logarithm of minimal angle of resolution) scale. The results were then grouped into categories based roughly on the severity of acuity deficits: normal $(>0.7$ to 1$)$, mild deficit $(0.5$ to 0.7$)$, and severe deficit $(0.1$ to $<0.5)$.

Ophthalmologic findings, including short palpebral fissure length, blepharoptosis, epicanthus, hypertelorism, strabismus, anterior segment abnormalities (ie, cataracts), nystagmus, blepharophimosis, microphthalmia, optic nerve hypoplasia, retinal vessel tortuosity, and other abnormalities of the fundus, were recorded. Determination of short palpebral fissure length (2 standard deviations below the mean) was made by comparing measurements to age-adjusted percentile standards in a US population published by Hall et al. ${ }^{21}$ The inner canthus to outer canthus measurements were obtained
Table I. Demographic characteristics of mothers and children exposed to heavy alcohol use prenatally and control children

\begin{tabular}{|c|c|c|c|}
\hline & $\begin{array}{l}\text { Exposed } \\
(n=43)\end{array}$ & $\begin{array}{l}\text { Unexposed } \\
\text { controls } \\
(n=55)\end{array}$ & $\boldsymbol{P}$ \\
\hline $\begin{array}{c}\text { Maternal age at delivery, } \\
\text { years, mean } \pm S D^{*}\end{array}$ & $23.0( \pm 6.5)$ & $25.6( \pm 6.7)$ & .06 \\
\hline$\leq 15$ years, $\mathrm{n}(\%)$ & I (2\%) & $0(0 \%)$ & \\
\hline 16 to 20 years, $\mathrm{n}(\%)$ & $20(47 \%)$ & $18(33 \%)$ & \\
\hline 21 to 25 years, $\mathrm{n}(\%)$ & $10(23 \%)$ & $12(22 \%)$ & \\
\hline 26 to 30 years, $n$ (\%) & $6(14 \%)$ & II (20\%) & \\
\hline 31 to 35 years, $n(\%)$ & $3(7 \%)$ & $9(16 \%)$ & \\
\hline 36 to 40 years, $n$ (\%) & $3(7 \%)$ & $5(9 \%)$ & \\
\hline Parity, n (\%) $\dagger$ & & & .18 \\
\hline Primiparous & $27(63 \%)$ & 27 (49\%) & \\
\hline Multiparous & $16(37 \%)$ & $28(51 \%)$ & \\
\hline $\begin{array}{l}\text { Years of school completed, } \\
\text { mean } \pm S D^{*}\end{array}$ & $10.2( \pm 3.3)$ & II.5 ( \pm 2.3$)$ & .02 \\
\hline Illiterate, n (\%) & I (2\%) & 0 & \\
\hline I to 7 years, $\mathrm{n}(\%)$ & $6(14 \%)$ & $3(5 \%)$ & \\
\hline 8 years, $\mathrm{n}(\%)$ & $6(14 \%)$ & $4(7 \%)$ & \\
\hline 9 to II years, $\mathrm{n}(\%)$ & $10(23 \%)$ & I $3(24 \%)$ & \\
\hline 12 years, $\mathrm{n}(\%)$ & 9 (21\%) & 21 (38\%) & \\
\hline$>12$ years, $n(\%)$ & II (26\%) & $14(25 \%)$ & \\
\hline Marital status, n (\%)† & & & .007 \\
\hline Single & $36(84 \%)$ & $32(58 \%)$ & \\
\hline Married & $5(13 \%)$ & $22(40 \%)$ & \\
\hline Divorced & $2(5 \%)$ & I (2\%) & \\
\hline Infant sex, n (\%)† & & & .19 \\
\hline Male & $26(60 \%)$ & $26(47 \%)$ & \\
\hline Female & 17 (40\%) & $29(53 \%)$ & \\
\hline $\begin{array}{l}\text { Gestational age, weeks, } \\
\text { mean } \pm \text { SD* }\end{array}$ & $39.3( \pm 0.9)$ & $39.2( \pm 1.0)$ & .52 \\
\hline Birth weight, g, mean $\pm S D^{*}$ & $3405( \pm 418)$ & $3458( \pm 351)$ & .516 \\
\hline $\begin{array}{l}\text { Age at time of exam, years, } \\
\text { mean } \pm S D^{*}\end{array}$ & $6.3( \pm 1.3)$ & $5.6( \pm 1.2)$ & .005 \\
\hline
\end{tabular}

*Student $t$-test.

$\dagger \chi^{2}$ test.

in millimeters with a rigid ruler with the examiner seated directly in front of the subject.

\section{Statistical Analysis}

Categorical demographic variables were compared using the $\chi^{2}$ test, and continuous variables were compared using Student's t-test. SAS version 9.1 (SAS Institute, Cary, North Carolina) was used for these analyses. Ocular malformations and abnormalities were analyzed using $P$ values and 95\% confidence intervals (CIs) of the difference of proportions from the unconditional exact method for 2 binomial samples of StatXact 4 (Cytel, Cambridge, Massachusetts).

\section{RESULTS}

A total of 43 children of heavy-drinking mothers and 55 children of nondrinking mothers underwent ophthalmologic examination. The average alcohol exposure of the 


\begin{tabular}{|c|c|c|c|c|}
\hline Ocular abnormality & Exposed $(n=43), n(\%)$ & Unexposed $(n=55), n(\%)$ & $\mathbf{P}$ & $\begin{array}{l}\text { Exposed-unexposed } \\
\text { difference, \% }(95 \% \mathrm{Cl})\end{array}$ \\
\hline Increased arterial tortuosity & $7(16 \%)$ & $8(15 \%)$ & .88 & $(-15.9,23.8)$ \\
\hline Tilted optic disc & $0(0 \%)$ & I (2\%) & .79 & $(-16.8,10.5)$ \\
\hline Optic nerve hypoplasia & $0(0 \%)$ & $0(0 \%)$ & 1.00 & $(-12.9,11.9)$ \\
\hline Short palpebral fissure length & $6(14 \%)$ & $10(18 \%)$ & .66 & $(-25.8,14.3)$ \\
\hline Epicanthus & $9(21 \%)$ & $6(11 \%)$ & .33 & $(-7.8,31.7)$ \\
\hline Ptosis & I (2\%) & I (2\%) & .97 & $(-11.5,20.5)$ \\
\hline Positive kappa angle & $\mathrm{I}(2 \%)$ & $0(0 \%)$ & .79 & $(-8.4,21.0)$ \\
\hline Lateral ectropion & $\mathrm{I}(2 \%)$ & $0(0 \%)$ & .79 & $(-8.4,21.0)$ \\
\hline Convergence insufficiency & $0(0 \%)$ & $\mathrm{I}(2 \%)$ & .79 & $(-16.8,10.5)$ \\
\hline Cataract & $0(0 \%)$ & $2(4 \%)$ & .65 & $(-20.0,9.1)$ \\
\hline
\end{tabular}

\begin{tabular}{|c|c|c|c|c|}
\hline Mean refraction $($ mean $\pm S D)$ & Exposed $(n=43)$ & Controls $(n=51)$ & $P$ & Mean difference in diopters $(95 \% \mathrm{Cl})$ \\
\hline OD & $0.92 \pm 1.74$ & $1.05 \pm 0.61$ & .64 & $(-0.66,0.42)$ \\
\hline OS & $1.17 \pm 1.79$ & $1.07 \pm 0.67$ & .73 & $(-0.44,0.66)$ \\
\hline Refraction, n (\%) & Exposed $(n=43)$ & Controls $(n=5 \mathrm{I})$ & $P$ & Difference, \% (95\% Cl) \\
\hline Myopia & $\mathrm{I}(2 \%)$ & $0(0 \%)$ & .79 & $(-9.0,21.0)$ \\
\hline Astigmatism & $\mathrm{I}(2 \%)$ & I $(2 \%)$ & 1.00 & $(-12.1,20.8)$ \\
\hline Hyperopia & $8(19 \%)$ & $4(7 \%)$ & .29 & $(-6.7,32.6)$ \\
\hline Amblyopia & $\mathrm{I}(2 \%)$ & $0(0 \%)$ & .79 & $(-9.0,21.0)$ \\
\hline BCVA, n (\%) & Exposed $(n=38)$ & Controls $(n=45)$ & $P$ & Difference, \% (95\% Cl) \\
\hline Severe $(0.1$ to $<0.5)$ & $\mathrm{I}(3 \%)$ & I $(2 \%)$ & 1.00 & $(-13.6,22.9)$ \\
\hline Mild $(0.5$ to 0.7$)$ & I (3\%) & I (2\%)* & 1.00 & $(-13.6,22.9)$ \\
\hline Normal $(>0.7$ to 1.0$)$ & $36(95 \%)$ & $43(96 \%)$ & .95 & $(-23.9,14.7)$ \\
\hline
\end{tabular}

*OS only.

women in the exposed group was 9.7 standard drinks per day (range, 5.3 to 19.1) before knowledge of pregnancy. Even though this group decreased their alcohol intake during pregnancy, in most women this decrease was modest; the average intake was still 5.8 standard drinks per day throughout the remainder of pregnancy. Only 7 women (16\%) stopped drinking, 4 (9\%) early in the second trimester and 3 (7\%) during the third trimester. The unexposed controls were significantly younger (average age, 5.6 years) than the exposed subjects (average age, 6.3 years) $(P=.005)$, because matching the exposed subjects to controls took some time (Table I). Although statistically significant, the difference in mean age between the groups was only 0.75 years. The mothers of the exposed children completed significantly fewer years of school (10.2 years vs 11.5 years; $P=.024)$ and were significantly more likely to have single marital status $(P=.007)$. There were no significant differences between the 2 groups in terms of maternal age, parity, infant sex, gestational age at delivery, or birth weight.

\section{Fundoscopy}

The 2 groups exhibited no significant differences in the rate of retinal vessel tortuosity or optic nerve abnormalities (Table II). Seven exposed subjects and 8 controls had mild increased arteriolar tortuosity $(P=.88)$. One control had a tilted optic nerve, and 1 control had small paramacular pigmented lesions in the left eye. None of the subjects of either group demonstrated optic nerve hypoplasia, one of the serious abnormalities frequently reported in studies of children with FAS.

\section{External Ocular Examination, Optical Motility Assessment, and Slit-Lamp Examination}

External ocular examination, optical motility assessment, and slit-lamp examination revealed no statistically significant differences in findings between the 2 groups. The external ocular examination demonstrated the presence of short palpebral fissures in 14\% of the exposed subjects and $18 \%$ of the controls $(P=.66)$, epicanthus in $21 \%$ of the exposed subjects and $11 \%$ of the controls $(P=.33)$, and ptosis in 1 child in each group. One exposed child demonstrated a positive kappa angle, and 1 exhibited a lateral ectropion. One control child had convergence insufficiency. Two control children had cataracts. No other anterior segment abnormalities (eg, Axenfeld-Rieger anomaly, Peters anomaly, microcornea, shallow anterior chamber, congenital glaucoma, persistent hyaloids, corneal opacities) were seen in either group.

\section{Visual Acuity and Refraction}

BCVA ranged from 0.1 to 1.0 (Table III). Visual acuity was examined successfully in 38 exposed subjects and 45 
controls. Five exposed subjects and 10 controls were not able to cooperate with the visual acuity examination. Two exposed subjects exhibited abnormal BCVA bilaterally, 1 mild ( 0.5 to $0.7)$ and 1 severe $(<0.5)$. Two controls had abnormal BCVA, 1 mild $(0.5$ to 0.7$)$ in the left eye only, the other severe $(<0.5)$ bilaterally. Refraction determined under cycloplegia ranged from -1.25 to +5.75 (spherical equivalent). Mean refraction in the right eye was $0.92 \pm 1.74$ in the exposed group and $1.05 \pm 0.61$ in the control group $(P=.64)$. In the left eye, mean refraction was $1.17 \pm 1.79$ in the exposed group and $1.07 \pm 0.67$ in the control group $(P=.73)$. Refraction data were incomplete for 4 control subjects. Myopia was found in 1 exposed subject but in no controls. Astigmatism was present in 1 exposed subject and 1 control. Hyperopia, defined as $\geq 2.0$ diopters, was present in 8 exposed subjects and 4 controls $(P=.29)$. Hyperopia can be a normal developmental finding up to age 7 years. ${ }^{22}$ Three of the 8 exposed subjects and 1 of the 4 controls with hyperopia were age $\geq 7$ years at the time of the examination. Only 1 exposed subject with hyperopia was over age 7 years at the time of the examination. No statistically significant differences in visual acuity or refraction were detected between the exposed group and the controls.

\section{DISCUSSION}

The present study was conducted to determine the prevalence of visual and ocular abnormalities in an unselected cohort of Chilean children exposed to large quantities of alcohol in utero compared with matched controls. Major ocular anomalies and vision problems were no more common in our heavily alcohol-exposed children than in the unexposed controls. This finding is reassuring, given the high prevalence of ocular abnormalities reported previously in children diagnosed with FAS. $2,4,5,6,8,9,13-16,18,19,23-25$

Although many studies have reported a high rate of major eye malformations in children with FAS, little is known about children who are exposed to high levels of alcohol but do not develop FAS, despite the fact that most heavily alcohol-exposed children do not develop FAS. Only 2 previous studies of the visual system in alcohol-exposed children included children who did not have FAS. The first study of ocular abnormalities in alcohol-exposed children who did not have FAS included only 10 children who did not meet the criteria for FAS; of these children; 4 had eye abnormalities (maculopathy, tortuosity, esotropia, and nystagmus). ${ }^{16}$ But all of these children were siblings of children with FAS and thus may have been referred for evaluation because of eye problems. In the second study, Carter et $\mathrm{al}^{3}$ prospectively evaluated the effects of prenatal alcohol exposure on visual acuity in 131 South African infants at age 6.5 months. This study only assessed vision (using Teller acuity cards) and did not examine the ocular structures, however. This group reported an association between prenatal alcohol exposure and diminished visual acuity in infancy $(27.3 \%$ vs $9.3 \%$ of controls; $P<$ $.005){ }^{3}$ But because this study was limited by an incomplete eye examination, the authors were unable to determine the cause (eg, refractive error, retinal changes, central nervous system abnormalities) of the lower visual acuity scores in infants with prenatal alcohol exposure. The authors also made the important point that acuity deficits seen at age 6.5 months may reflect simply a maturational deficit or a delay in visual system development. They emphasized that their findings necessitate reevaluation by complete visual assessment later in childhood.

Most of what is known regarding ocular findings in children with FAS has been described by Stromland and coworkers, whose work has focused primarily on comprehensive examinations in children diagnosed with FAS. ${ }^{13-16,18,19,25,26}$ Stromland reported that most children with FAS exhibit ocular abnormalities, including optic disc hypoplasia (48\%) and retinal vessel tortuosity (49\%). ${ }^{13}$ These rates could be elevated by the fact that the children may have been referred for visual problems, however; moreover, the examiners were not masked to diagnosis.

Other data suggest that rates of ocular malformations are not as high as those reported from Sweden. A recent Portuguese study of 32 children with FAS and 25 controls reported retinal vessel tortuosity in $30 \%$ and optic nerve hypoplasia in $25 \%$ of the children with FAS, lower rates than reported from Sweden. ${ }^{11}$ This group also noted that their patients had better visual acuity ( $82.7 \%$ with normal acuity vs $35 \%$ in the Swedish study), and that the malformations were notably less severe than those seen in the Swedish study. ${ }^{13}$ The authors suggested that referral/selection bias, drinking patterns, and genetic factors may play significant roles in the varying rates and severity of abnormalities.

Our data suggest that the high rate of anomalies found by Stromland and coworkers and others might be due, at least in part, to the way in which subjects were selected, and that the results of Carter et $\mathrm{al}^{3}$ may have been due to maturational delay. A possible explanation for the low incidence of ocular abnormalities in our study group is that exposure was based on maternal prenatal alcohol use, not on FAS. It is likely that only those subjects with FAS have high rates of ocular abnormalities. The mothers of the exposed subjects were young (mean age, 23.02 years), and most of our women were primiparous (63\%), potentially attenuating the damaging effects of alcohol. Increased maternal age and parity have been directly correlated with the severity of defects caused by prenatal alcohol exposure in both animal and human studies. ${ }^{27-30}$ It is also possible that some of the mothers decreased their alcohol consumption because of their enrollment in this study, and that defects involving the growth and development of ocular structures (eg, growth of the optic nerve and retinal vessels) may have been averted by this decrease in alcohol consumption. Most mothers in our cohort did not significantly reduce their drinking after study entry, however. Genetic or nutritional differences between the study populations also might affect the risk of damage to the developing visual system secondary to exposure to alcohol. ${ }^{31-33}$

This prospective study examined the ocular structures and visual function comprehensively in unselected children 
with prenatal alcohol exposure and unexposed controls. Eye examinations were performed on all exposed subjects, not just those who had phenotypic changes related to alcohol damage. The ophthalmologist was masked to the subjects' exposure status. The study has some limitations. It was designed to examine the effects of heavy alcohol exposure prenatally; our small number of children does not allow us to evaluate the frequency of eye malformations in children with FAS. The reference population used for palpebral fissures was not standardized for the Chilean population, and there are no published data regarding ethnic differences in palpebral fissure lengths in the Chilean population; therefore, we cannot rule out the possibility that ethnic differences are the reason for the high rate of short palpebral fissure. The relatively high prevalence of short palpebral fissure length and epicanthal folds in both the exposed and the control groups may represent a normal variant in this population. Although the precise reason for these findings remains unclear, we postulate that the young age of the subjects, in combination with the ethnic differences in the Chilean population, is the most likely rationale. Palpebral fissures are known to vary in size according to ethnicity and age. ${ }^{34,35}$ Moreover, lack of cooperation in our young subjects could have caused some measurement error. We were also limited by our inability to get many of the subjects to return for eye examinations because of difficulty in contacting them.

The high frequency of ocular and visual abnormalities reported in children with FAS has led some to advocate ophthalmologic examinations as a diagnostic tool for FASD. Our data indicate that ophthalmologic examinations are not likely to help diagnose FASD, but they may be important in the assessment/evaluation of a child who has FAS.

In summary, our findings demonstrate that the teratogenic effect of alcohol on the developing visual system is likely limited to children who have FAS and not extended to children with high prenatal alcohol exposure who do not develop FAS. These findings have several potentially important clinical implications, including that eye examinations are unlikely to help clarify the diagnosis in children with suspected alcohol-related damage, and that children who do not have classic FAS are not at high risk for eye abnormalities.

\section{REFERENCES}

1. Jones KL, Smith DW, Ulleland CN, Streissguth P. Pattern of malformation in offspring of chronic alcoholic mothers. Lancet 1973;1:1267-71.

2. Altman B. Fetal alcohol syndrome. J Pediatr Ophthalmol 1976;13:255-8.

3. Carter RC, Jacobson SW, Molteno CD, Chiodo LM, Viljoen D, Jacobson JL. Effects of prenatal alcohol exposure on infant visual acuity. J Pediatr 2005;147:473-9.

4. Chan T, Bowell R, O'Keefe M, Lanigan B. Ocular manifestations in fetal alcohol syndrome. Br J Ophthalmol 1991;75:524-6.

5. Gonzalez ER. New ophthalmic findings in fetal alcohol syndrome. JAMA 1981;245:108.
6. Hellstrom A, Chen Y, Stromland K. Fundus morphology assessed by digital image analysis in children with fetal alcohol syndrome. J Pediatr Ophthalmol Strabismus 1997;34:17-23.

7. Hellstrom A, Wiklund LM, Svensson E. The clinical and morphologic spectrum of optic nerve hypoplasia. J AAPOS 1999;3:212-20.

8. Miller M, Israel J, Cuttone J. Fetal alcohol syndrome. J Pediatr Ophthalmol Strabismus 1981;18:6-15

9. Miller MT, Epstein RJ, Sugar J, Pinchoff BS, Sugar A, Gammon JA, et al. Anterior segment anomalies associated with the fetal alcohol syndrome. J Pediatr Ophthalmol Strabismus 1984;21:8-18.

10. Pinazo-Duran MD, Renau-Piqueras J, Guerri C, Stromland K. Optic nerve hypoplasia in fetal alcohol syndrome: an update. Eur J Ophthalmol 1997;7:262-70.

11. Ribeiro IM, Vale PJ, Tenedorio PA, Rodrigues PA, Bilhoto MA, Pereira HC. Ocular manifestations in fetal alcohol syndrome. Eur J Ophthalmol 2007;17:104-9.

12. Stromland K. Eyeground malformations in the fetal alcohol syndrome. Birth Defects Orig Article Ser 1982;18:651-5.

13. Stromland K. Ocular abnormalities in the fetal alcohol syndrome. Acta Ophthalmol Suppl 1985;171:1-50.

14. Stromland K. Ocular involvement in the fetal alcohol syndrome. Surv Ophthalmol 1987;31:277-84

15. Stromland K, Hellstrom A, Gustavsson T. Morphometry of the optic nerve and retinal vessels in children by computer-assisted image analysis of fundus photographs. Graefes Arch Clin Exp Ophthalmol 1995;233:150-3.

16. Stromland K, Sundelin K. Paediatric and ophthalmologic observations in offspring of alcohol-abusing mothers. Acta Paediatr 1996;85:1463-8.

17. Stromland K, Pinazo-Duran MD. Ophthalmic involvement in the fetal alcohol syndrome: clinical and animal model studies. Alcohol Alcohol 2002;37:2-8.

18. Stromland K. Visual impairment and ocular abnormalities in children with fetal alcohol syndrome. Addict Biol 2004;9:153-7.

19. Stromland K. Eyeground malformations in the fetal alcohol syndrome. Neuropediatrics 1981;12:97-8.

20. Aros S, Mills JL, Torres C, Henriquez C, Fuentes A, Capurro T, et al. Prospective identification of pregnant women drinking four or more standard drinks ( $\geq 48 \mathrm{~g}$ ) of alcohol per day. Substance Use Misuse 2006;41:183-97.

21. Hall J, Froster-Iskenius U, Allanson J. Handbook of Normal Physical Measurement. New York: Oxford University Press; 1989.

22. Behrman RE, Kliegman RM, Jenson HB. Nelson's Textbook of Pediatrics. 17th edition. Philadelphia: WB Saunders; 2007.

23. Garber JM. Steep corneal curvature: a fetal alcohol syndrome landmark. J Am Optom Assoc 1984;55:595-8.

24. Hug TE, Fitzgerald KM, Cibis GW. Clinical and electroretinographic findings in fetal alcohol syndrome. J AAPOS 2000;4:200-4

25. Stromland K. Contribution of ocular examination to the diagnosis of foetal alcohol syndrome in mentally retarded children. J Mental Defic Res 1990;34(Pt 5):429-35.

26. Stromland K, Hellstrom A. Fetal alcohol syndrome: an ophthalmological and socioeducational prospective study. Pediatrics 1996;97(6 Pt 1):845-50.

27. May PA, Gossage JP, Brooke LE, Snell CL, Marais AS, Hendricks LS, et al. Maternal risk factors for fetal alcohol syndrome in the Western Cape province of South Africa: a population-based study. Am J Public Health 2005;95:1190-9.

28. Jacobson JL, Jacobson SW, Sokol RJ. Increased vulnerability to alcohol-related birth defects in the offspring of mothers over 30. Alcohol Clin Exp Res 1996;20:359-63.

29. Abel EL, Dintcheff BA. Factors affecting the outcome of maternal alcohol exposure, I: parity. Neurobehav Toxicol Teratol 1984;6:373-7.

30. Abel EL, Dintcheff BA. Factors affecting the outcome of maternal alcohol exposure, II:/ maternal age. Neurobehav Toxicol Teratol 1985;7:263-6.

31. Green RF, Stoler JM. Alcohol dehydrogenase 1B genotype and fetal alcohol syndrome: a HuGE minireview. Am J Obstet Gynecol 2007;197:12-25.

32. Gemma S, Vichi S, Testai E. Metabolic and genetic factors contributing to alcohol induced effects and fetal alcohol syndrome. Neurosci Biobehav Rev 2007;31:221-9.

33. Das UN. Fetal alcohol syndrome and essential fatty acids. PLoS Med 2006;3:e247. 34. Leung AK, Ma KC, Siu TO, Robson WL. Palpebral fissure length in Chinese newborn infants: Comparison with other ethnic groups. Clin Pediatr (Phila) 1990; 29:172-4.

35. Paiva RS, Minare-Filho AM, Cruz AA. Palpebral fissures changes in early childhood. J Pediatr Ophthalmol Strabismus 2001;38:219-23. 